\title{
Oral health assessment for users of marijuana and cocaine/crack substances
}

\section{Mariane Beatriz SORDI(a) Rachel Captzan MASSOCHIN(a) Alessandra Rodrigues de CAMARGO(a) Tadeu LEMOS ${ }^{(b)}$ Etiene de Andrade MUNHOZ(a)}

(a) Universidade Federal de Santa Catarina UFSC, Health Science Centre, Department of Stomatology, Florianópolis, SC, Brazil.

(b) Universidade Federal de Santa Catarina UFSC, Biological Science Centre, Department of Pharmacology, Florianópolis, SC, Brazil.

Declaration of Interest: The authors certify that they have no commercial or associative interest that represents a conflict of interest in connection with the manuscript.

Corresponding Author:

Etiene de Andrade Munhoz etiamfob@yahoo.com

https://doi.org/10.1590/1807-3107BOR-2017.vol31.0102

Submitted: July 29, 2017

Accepted for publication: Oct 10, 2017

Last revision: Nov 07, 2017
Abstract: The objective of this study was to assess the oral health status of users of illicit drugs such as marijuana and cocaine/crack and compare it with individuals not using these chemical substances. Questionnaires were applied to 35 illicit drugs users to gather information on demographic status, general health, and use of drugs. Then, a clinical assessment of the oral health condition was performed to collect data on decayed, missing and filled teeth (DMFT) index, salivary flow rate (SFR), and mucosal lesions. The control group was composed of 35 non-illicit drug users. In the experimental group, $91.43 \%$ were males, $80 \%$ were smokers, and $42.85 \%$ were alcoholics. Cocaine was the most common drug used $(77.15 \%)$, followed by marijuana (68.6\%), and crack (51.4\%). The average DMFT index was 9.8 and the SFR was reduced in $60 \%$ of subjects. Mucosal alterations were detected, but no potentially malignant disorders or oral cancer were diagnosed. Compared to control group, significantly higher values for gender $(40 \%, \mathrm{p}=0.0001)$, smoking $(22.86 \%)$ and heavy drinking $(5.7 \%)$ habits $(p=0.0001)$, SFR (31.4\%; $p=0.0308)$, and oral lesions $(p=0.0488)$ were found for the experimental group, although significantly higher values were found in the control group for DMFT index $(p=0.0148)$. It can be concluded that the use of illicit drugs contributed to an increased prevalence of oral mucosa lesions. In addition, a decline on SFR and a reduced DMFT index was observed for illicit drug users.

Keywords: Street Drugs; Mouth Neoplasms; Oral Health; Saliva.

\section{Introduction}

According to the United Nations Office on Drug and Crime, it is estimated that, worldwide, 243 million people aged 15 to 64 are users of some illicit drug, which leads to approximately 5.000 drug-related deaths per year in Latin America and the Caribbean. The World Health Organization (WHO) Expert Committee on Drug Dependence defines a psychoactive drug as a chemical, whether natural or synthetic, that when taken by any route (inhalation, ingestion, intramuscular, intravenous) acts on the central nervous system, producing physical and/or psychiatric alterations, generating altered sensations, or modifying the psychological state, i.e., altering the person's behavior. Currently, there is a sharp increase in the misuse of psychoactive substances (PAS), which can produce severe physical and mental effects, 
resulting in individual, family, and social conflicts, with serious impacts on society. ${ }^{1}$

Cannabis sativa, also known as marijuana, is the most commonly used drug worldwide among all PAS. Marijuana users have greater oral cavity deterioration than non-users, with increased risk of caries and periodontal disease. ${ }^{2,3}$ Higher levels of decayed, missing and filled teeth (DMFT) and bacterial plaque indices have been found in marijuana users than in non-users. ${ }^{1,4}$ Moreover, users are more prone to oral infections, possibly due to alterations in oral immunology, ${ }^{2}$ and drug use can be associated with dysplastic changes and potentially malignant disorders of the oral mucosa, increasing the incidence of squamous cell carcinoma. ${ }^{5}$ Marijuana cigarettes can contain up to twice the amount of polycyclic aromatic hydrocarbons as tobacco cigarettes, and the usual consumption without a filter leads to a higher concentration of inhaled smoke. However, the relationship between marijuana use and oral cancer is still not clear. ${ }^{6}$ The association between marijuana and oropharyngeal and tongue cancers suggests that the biological effects of $C$. sativa are pro- and anti-carcinogenic. ${ }^{5}$ Marks et al..$^{5}$ observed that $C$. sativa play a role in immune cells, suppressing pro-inflammatory cytokine production and enhancing anti-inflammatory cytokine production, leading to reduced host immune responses as well as suppression of anti-tumor immunity. Additionally, it has also been shown in epithelial cell lines that marijuana has antitumor effects through the arrest of uncontrolled cell growth, enhancement of apoptosis, downregulation of angiogenesis, and cellular migration.

Cocaine (Erythroxylon coca) is another PAS widely used around the world that was proved to induce significant changes in epithelial cells of oral mucosa.? The nuclear area and the ratio between nuclear area and the cytoplasmic area of stratified squamous epithelium cells of the oral mucosa were reduced in cocaine or crack users; this reduction was associated with the higher rate of keratinization in these individuals. ${ }^{78}$ Inflammatory changes were induced in the oral epithelium of cocaine/crack users. ${ }^{8}$ When rubbed on the gum surface for rapid absorption, cocaine powder can cause mucosal irritation. The mucosal absorption of $E$. coca can lead to oral lesions as a consequence of decreased blood supply due to vasoconstriction of the affected region, resulting in tissue necrosis. ${ }^{7}$ Nevertheless, the relationship of cocaine/crack use and their effects on the mouth is scarcely discussed in the scientific literature.

Data from the II Brazilian National Alcohol and Drugs Survey indicated a prevalence of approximately $4 \%$ of marijuana use among adolescents and there are reports of increasing dependence. ${ }^{9}$ Regarding cocaine and crack, $1.7 \%$ of Brazilians have used intranasal cocaine and approximately $0.8 \%$ reported smoking cocaine in the form of crack. The prevalence of intravenous drug use in Brazil was considered very low. ${ }^{10}$ The frequent use of illicit drugs leads to various social and individual complications, such as risky behavior, violence, and other problems, that interfere directly with an individual's health. However, substance abuse also contributes to other consequences including decreased oral health resulting from bad hygiene habits, a trend to increased consumption of sweets, irregular eating patterns, malnutrition, and infrequent visits to the dentist. ${ }^{11}$ Moreover, poor oral health had a substantial impact on the daily functioning of individuals addicted to alcohol and/or drugs. ${ }^{4}$

A low quality of life of psychoactive substances users is related to a high DMFT index and low income, among other factors. Thus, strategies to promote oral health in these individuals are necessary to assist in the rehabilitation of drug users. ${ }^{4}$ Dentists can evaluate oral alterations that might be related to drug use, such as enamel erosion caused by contact with cocaine/crack, the presence of generalized inflammation of the oral mucosa caused by marijuana, as well as dry mouth, gingival/periodontal disease and tooth decay as a result of poor oral hygiene. ${ }^{3,4,8,12}$

The relationship between illicit drug use and oral tissues response is lacking in the literature. Therefore, the aim of this study was to compare the oral health status of users of illicit drugs, such as marijuana and cocaine/crack, with that of non-users. It was hypothesized that the use of these substances might lead to the development of mucosal lesions.

\section{Material and methods}

This cross-sectional study was performed between March and September of 2014, after approval by the Ethics Committee on Human Research of the 
Federal University of Santa Catarina, Brazil (CAAE 22723713.7.0000.0121, date of approval 12/09/2013). Data collection was undertaken with the written consent from each subject and according to the ethical principles.

Thirty-five patients of 18 years of age or older, of both genders, users of some kind of illicit chemical substance, and under treatment at the Psychiatric Unit of the Hospital of the Federal University of Santa Catarina (HU/UFSC) and at the Psychiatric Institute of Santa Catarina (IPq/SC) were evaluated as the experimental group. Individual users of marijuana (smoked), cocaine (intravenous or inhaled) and/or crack (inhaled) were included in the present study. Polydrug users and the concomitant users of legal substances, such as tobacco and alcohol, were also included in the experimental group. The control group was composed of 35 patients under treatment at the Dental School of the Federal University of Santa Catarina who were above 18 years of age, of both genders, and did not use any kind of illicit chemical substance. Patients were randomly selected and subjects who used legal substances, such as tobacco and alcohol, were not excluded from the sample. The recruitment sites were selected by convenience, once both institutions are reference centers for treatment of chemical dependency; individuals were selected randomly according to their attendance to the institutions. Data were collected in a period of 6 months.

A questionnaire was developed specifically for this study and was applied by two calibrated examiners to all patients (both experimental and control groups) to investigate the socioeconomic and demographic status, general health (comorbidities, hospitalizations, surgeries, allergies, and use of medication), use of legal and illegal drugs, and time and frequency of use. All data reported by the participants were considered. Completion of the questionnaire was followed by a clinical assessment of the oral health condition. Decayed, missing and filled teeth (DMFT index), salivary flow rate (SFR) by the tongue depressor adherence test and presence of mucosal lesions were the variables used to assess the oral health status by the examiners. Two stomatology professors conducted the calibration of the examiners. The same professors developed the clinical assessment protocol.
The diagnosis of oral lesions was based on clinical evaluation at the time of the interview. Complementary imaging, laboratory, or histopathological exams were requested when necessary. All patients received full support regarding diagnosed lesions. The SFR test was performed by placing a wooden tongue depressor on the buccal mucosa and assessing its adhesiveness. This method is reported in the literature as an easy maneuver to detect hyposalivation. ${ }^{13}$

All data obtained from the questionnaires and the oral examinations were statistically analyzed using the SPSS v.16.0 software for Windows (SPSS, Chicago, USA). The Kolmogorov and Smirnov test was used to confirm the Gaussian distribution of the samples. The confidence interval was set to $95 \%$ $(p<0.05)$. Clinical data were analyzed descriptively with relative and absolute variables. The difference between groups regarding gender, smoking and drinking habits, use of medication, comorbidities, DMFT index, SFR, and the presence of mucosal lesions were analyzed using the chi-square test.

\section{Results}

\section{Demographic and socioeconomic data}

In the experimental group, 32 (91.43\%) individuals were male with mean age of 36 years; 29 (82.85\%) were Caucasian, while 6 were Black. In the control group, $14(40 \%)$ subjects were male with mean age of 45 years; 29 were Caucasian, 5 were Black, and 1 was Asian. A statistical difference was found regarding gender $(p=0.0001)$. Additional demographic and socioeconomic data can be found in Table 1 .

\section{General health}

Data regarding the presence of comorbidities, hospitalizations, surgeries, and allergies in the studied groups are presented in Table 2. No difference was found between groups.

\section{Use of legal substances}

The use of legal chemical drugs in experimental and control groups are presented in Table 3 . In the experimental group, the smoking habit of current and ex-smokers had lasted approximately 18 years, and the average consumption was 22.15 cigarettes per day. 
- Oral health assessment for users of marijuana and cocaine/crack substances

Table 1. Demographic and socioeconomic data.

\begin{tabular}{|c|c|c|c|c|c|c|}
\hline \multirow{2}{*}{ Variables } & \multicolumn{3}{|c|}{ Experimental Group } & \multicolumn{3}{|c|}{ Control Group } \\
\hline & Female $(n=3)$ & Male $(n=32)$ & Total $(n=35)$ & Female $(n=3)$ & Male $(n=32)$ & Total $(n=35)$ \\
\hline \multicolumn{7}{|l|}{ Age } \\
\hline Mean & 37.65 & 34.34 & 35.95 & 43.95 & 42.35 & 45.11 \\
\hline Variation & $28-48$ & $19-56$ & $19-56$ & $21-83$ & $23-70$ & $21-83$ \\
\hline$p$ value & \multicolumn{6}{|c|}{0.0001} \\
\hline \multicolumn{7}{|l|}{ Ethnicity } \\
\hline White Skin & 3 & 26 & 29 & 18 & 11 & 29 \\
\hline Black Skin & 0 & 6 & 6 & 2 & 3 & 5 \\
\hline Asian & 0 & 0 & 1 & 1 & 0 & 1 \\
\hline \multicolumn{7}{|l|}{ Marital status } \\
\hline Single & 3 & 21 & 24 & 8 & 6 & 14 \\
\hline Married & 0 & 9 & 8 & 10 & 8 & 18 \\
\hline Divorced & 0 & 1 & 1 & 0 & 0 & 0 \\
\hline Widower & 0 & 0 & 0 & 3 & 0 & 3 \\
\hline Common-law & 0 & 1 & 2 & 0 & 0 & 0 \\
\hline \multicolumn{7}{|l|}{ Living arrangement } \\
\hline Spouse/children & 3 & 12 & 15 & 12 & 8 & 20 \\
\hline Parents & 0 & 13 & 13 & 4 & 2 & 6 \\
\hline Alone & 0 & 4 & 4 & 4 & 3 & 7 \\
\hline Homeless & 0 & 2 & 2 & 0 & 0 & 0 \\
\hline Others & 0 & 1 & 1 & 1 & 1 & 2 \\
\hline \multicolumn{7}{|c|}{ Habitants per habitation } \\
\hline Mean & 3.66 & 3.63 & 3.3 & 2.95 & 4.71 & 3.85 \\
\hline Variation & $2-6$ & $1-5$ & $1-6$ & $1-6$ & $1-36$ & $1-36$ \\
\hline Rest home & 0 & 0 & 0 & 0 & 1 & 1 \\
\hline \multicolumn{7}{|l|}{ Education level } \\
\hline None & 0 & 1 & 1 & 0 & 0 & 0 \\
\hline Primary school & 2 & 19 & 21 & 10 & 6 & 16 \\
\hline High school & 0 & 8 & 8 & 6 & 5 & 11 \\
\hline Technical course & 0 & 1 & 1 & 0 & 0 & 0 \\
\hline College & 1 & 3 & 4 & 5 & 3 & 8 \\
\hline
\end{tabular}

Table 2. General health data.

\begin{tabular}{|c|c|c|c|}
\hline \multirow{2}{*}{ Variables } & Experimental group & Control group & \multirow{2}{*}{$\mathrm{p}$-value } \\
\hline & $(n=35)$ & $(n=35)$ & \\
\hline \multicolumn{4}{|c|}{ Comorbidities } \\
\hline Yes & 8 & 10 & 0.7845 \\
\hline No & 27 & 25 & \\
\hline \multicolumn{4}{|c|}{ Hospitalizations } \\
\hline Yes & 21 & 17 & 0.4717 \\
\hline No & 14 & 18 & \\
\hline \multicolumn{4}{|l|}{ Surgeries } \\
\hline Yes & 11 & 14 & 0.6179 \\
\hline No & 24 & 21 & \\
\hline \multicolumn{4}{|l|}{ Allergies } \\
\hline Yes & 6 & 2 & 0.2597 \\
\hline No & 29 & 33 & \\
\hline \multicolumn{4}{|c|}{ Use of medications } \\
\hline Yes & 24 & 16 & 0.0909 \\
\hline No & 11 & 19 & \\
\hline
\end{tabular}


Table 3. Legal chemical substances data.

\begin{tabular}{|c|c|c|c|c|c|c|}
\hline \multirow{3}{*}{ Variables } & \multicolumn{6}{|c|}{ Experimental group } \\
\hline & Female & Male & Total & Female & Male & Total \\
\hline & $(n=3)$ & $(n=32)$ & $(n=35)$ & $(n=21)$ & $(n=14)$ & $(n=35)$ \\
\hline \multicolumn{7}{|l|}{ Smoking } \\
\hline Smoker & $2(5.7 \%)$ & $26(74.3 \%)$ & $28^{\text {Aac }}$ & $4(11.43 \%)$ & $4(11.43 \%)$ & $8^{A b}$ \\
\hline Ex-smoker & 1 (2.85\%) & $1(2.85 \%)$ & $2^{\mathrm{Bb}}$ & $3(8.6 \%)$ & $6(17.14 \%)$ & $9^{B}$ \\
\hline Non-smoker & 0 & 5 (14.3\%) & $5^{\mathrm{aC}}$ & 14 (40\%) & $4(11.43 \%)$ & $18^{\mathrm{cc}}$ \\
\hline \multicolumn{7}{|l|}{ Alcoholism } \\
\hline Alcoholic & 1 (2.85\%) & $14(40 \%)$ & $15^{\mathrm{Aa}}$ & $1(2.85 \%)$ & $1(2.85 \%)$ & $2^{A b}$ \\
\hline Ex-alcoholic & $1(2.85 \%)$ & $11(31.45 \%)$ & $12^{\mathrm{B}}$ & 0 & $1(2.85 \%)$ & $1^{\mathrm{B}}$ \\
\hline Non-alcoholic & $1(2.85 \%)$ & $7(20 \%)$ & $8^{a C}$ & $20(57,15 \%)$ & 12 (34.3\%) & $32^{c_{c}}$ \\
\hline Smoker and alcoholic (including ex-user) & 2 & 21 & 23 & 0 & 2 & 2 \\
\hline
\end{tabular}

In the control group, the average smoking duration was 15.4 years, and the average amount was 15.3 cigarettes per day. A statistical difference was found between groups with respect to smoking $(p=0.0001)$. The group of smokers in the experimental group was larger than the group of non-smokers $(p=0.0001)$ and ex-smokers $(p=0.0012)$ in the control group.

Uppercase letters represent significant differences between experimental and control groups and lowercase letters represent differences between the variables. Statistical difference was found between experimental and control groups with respect to the habit of smoking $(\mathrm{p}=0.0001)$. The group of smokers in the experimental group was higher than the group of non-smokers $(p=0.0001)$ and ex-smokers $(p=0.0012)$ in the control group. There was no difference between non-smokers and ex-smokers $(p=0.8311)$. Statistical difference was found between the experimental and control groups regarding alcohol consumption $(p=0.0001)$. The alcoholics group was higher in the experimental group $(\mathrm{p}=$ 0.0001 ) and the ex-alcoholics in the experimental group was higher than the non-alcoholics in the control group $(p=0.0001)$. There were no differences between alcoholics and ex-alcoholics $(p=0.806)$.

The average duration of alcohol consumption among alcoholics and ex-alcoholics was 18.7 years with a daily average of 2 liters in the experimental group, and in the control group was 7.5 years and daily average intake below 0.5 liters. Fermented (beer) and distilled (brandy, vodka) beverages were the most consumed in both groups. A statistical difference was determined between the experimental and control groups regarding alcohol consumption $(p=0.0001)$. The proportion of alcoholics $(p=0.0001)$ and ex-alcoholics in the experimental group was higher than the non-alcoholics in the control group $(p=0.0001)$.

\section{Use of illegal chemical substances}

In the experimental group, 24 (68.6\%) participants used marijuana, 27 (77.15\%) used cocaine, 18 (51.4\%) used crack, and $5(14.3 \%)$ used other illicit drugs. Twenty-two (62.85\%) individuals used more than one drug concurrently, and $34(97.15 \%)$ reported the combined use of legal and illegal drugs (Table 4). Figure 1 illustrates the concomitant use of legal and illegal drugs.

Of the 24 marijuana users, 12 (34.3\%) were active users and 12 (34.3\%) were abstinent. The average lifetime use of marijuana was 4.4 joints (cigarettes) per day for 13.3 years; the average abstinence period was 8.3 years. Of the 27 cocaine users, 10 (28.57\%) were still consuming the drug at the time of interview and $17(48.57 \%)$ had stopped using cocaine. The average lifetime use of cocaine was 13.1 years, the average amount of daily intake was $3.6 \mathrm{~g}$, and the average drug-free time was 2 years. Of the 18 crack users, 7 (20\%) were abstinent and 11 (31.4\%) still used the drug. The average lifetime use of crack was 7.2 years, the average amount consumed was $11 \mathrm{~g}$ per day, and the average withdrawal time was 2.75 years. Five users were consuming an illicit substance other than marijuana, cocaine or crack, which included lysergic acid diethylamide (LSD), ether spray (mixture of ether and chloroform), and ecstasy (3,4-methylenedioxymethamphetamine or MDMA). 
Table 4. Illegal chemical substances data.

\begin{tabular}{|c|c|c|c|}
\hline \multirow{2}{*}{ Variable } & Female & Male & Total \\
\hline & $(n=3)$ & $(n=32)$ & $(n=35)$ \\
\hline \multicolumn{4}{|l|}{ Marijuana } \\
\hline Users & 2 & 10 & 12 (34.3\%) \\
\hline Ex-users & 0 & 12 & 12 (34.3\%) \\
\hline Never used & 1 & 10 & 11 (31.4\%) \\
\hline \multicolumn{4}{|l|}{ Cocaine } \\
\hline Users & 2 & 8 & $10(28.6 \%)$ \\
\hline Ex-users & 0 & 17 & 17 (48.6\%) \\
\hline Never used & 1 & 7 & 8 (22.8\%) \\
\hline \multicolumn{4}{|l|}{ Crack } \\
\hline Users & 1 & 10 & 11 (31.4\%) \\
\hline Ex-users & 1 & 6 & 7 (20\%) \\
\hline Never used & 1 & 16 & 17 (48.6\%) \\
\hline \multicolumn{4}{|l|}{ Others } \\
\hline Users & 0 & 3 & $3(8.6 \%)$ \\
\hline Ex-users & 0 & 2 & $2(5.7 \%)$ \\
\hline Never used & 3 & 27 & 30 (85.7\%) \\
\hline \multicolumn{4}{|l|}{ Concomitant use } \\
\hline Legal and illegal & 3 & 31 & 34 \\
\hline Illegal & 2 & 20 & 22 \\
\hline
\end{tabular}

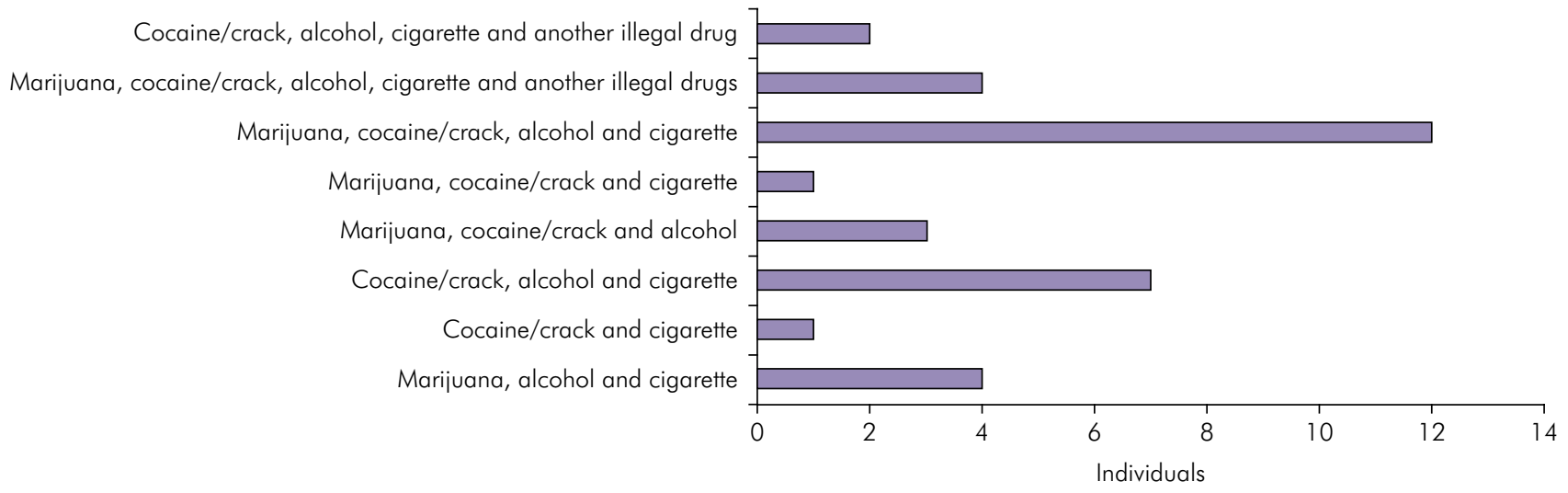

Figure 1. Concomitant use of legal and illegal drugs.

\section{Oral health evaluation}

Data on DMFT index, SFR, and mucosal lesions are presented in Figure 2. In the experimental group, the overall average DMFT was 9.8. Twenty-one (60\%) subjects had one or more decayed teeth (1.4), 24 (68.6\%) had one or more missing teeth (4.2), and 27 (77.1\%) presented one or more filled teeth (4.2). Twenty-one $(60 \%)$ individuals had a decreased SFR while $14(40 \%)$ had normal SFR. No lesions with a potential diagnosis of oral cancer or potentially malignant lesions were observed; however, several mucosal alterations, such as aphthous stomatitis $(n=1)$, frictional keratosis $(n=6)$, candidiasis $(n=1)$, tooth extraction scars $(n=1)$, and tongue depapillation $(n=1)$ were detected.

In the control group, the average DMFT was 12.3. Ten $(28.6 \%)$ individuals had one or more decayed teeth (1.05), 26 (74.3\%) had one or more missing teeth (6.54), and $30(85.7 \%)$ had one or more filled teeth (4.57). Eleven (31.4\%) subjects had a reduced SFR, while 24 (68.6\%) patients showed no reduction. Two cases of frictional keratosis were observed, but none with a probable diagnosis of oral cancer or potentially 

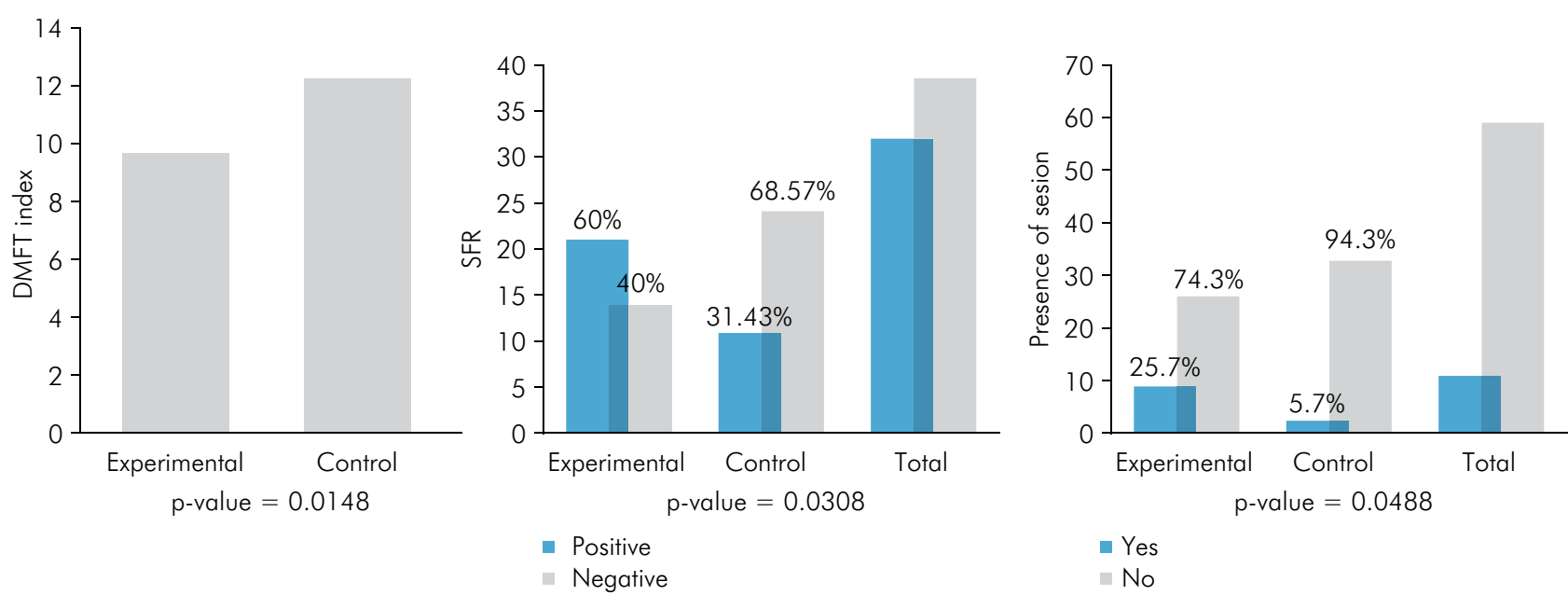

Figure 2. Oral health data.

malignant lesion. Significantly more patients with decreased SFR $(p=0.0308)$ and with mucosal lesions $(p=0.0488)$ were found in the experimental group. Significantly higher values for DMFT were found in the control group $(p=0.0148)$.

\section{Discussion}

Drug abuse is a public health problem for which preventive health strategies should be developed. Few studies address the relationship between use of illicit chemical drugs and oral health-tooth decay, reduced SFR, and mucosal lesions. Thus, the focus of this study was to determine the oral health status and the presence of mucosal lesions in association with demographics and overall health in drug addicts. A higher prevalence of mucosal lesions and a reduced SFR was found for illicit drug users, as well as in patients with higher smoking and drinking frequency.

The methodology adopted in the present study was based on the study conducted by Mateos-Moreno et al. ${ }^{14}$ This type of methodology is not commonly applied in studies with users of illicit drugs, such as cocaine, crack, and marijuana. However, similar methodologies were largely applied to study users of legal drugs, such as tobacco and alcohol. ${ }^{15,16,17} \mathrm{~A}$ similar study conducted in Brazil was recently published, ${ }^{4}$ in which the aim was to evaluate the impact of oral health conditions, socioeconomic status and use of specific substances on quality of life of alcohol and drug addicts.
Regarding the demographic data, a statistical difference was found for gender: men were more frequent in the experimental group than in the control group. This might be because one of the data collection points (IPq/SC) admit men only or because women take better care of their general health and attend medical/ dental check-ups more often. The average age for the experimental group was 36 years, while the average for the control group was 45 years. Drug use, abuse, and addiction can start at a young age, as proved in this study. In Brazil, the average age for starting drug consumption is 16.5 years old..$^{18}$ All subjects were in psychiatric treatment or were hospitalized.

No statistical difference was found for general health and comorbidities between groups. Systemic arterial hypertension was the most prevalent disease in both groups. In Brazil, $20 \%$ of the population has hypertension, ${ }^{19}$ which explains the high incidence of this comorbidity in the analyzed population. Use of a larger number of legal medications, such as antipsychotics/neuroleptics, anticonvulsants/ antiepileptics, antidepressants, anxiolytics, and vitamin complexes (mainly vitamin B complex) was found in the experimental group. However, for this analysis, the use of any drug was considered, regardless of the dosage, therefore no statistical difference existed between groups. Most of the above drugs are used in the treatment against drug addiction. ${ }^{14}$ Vitamin $B$ complex is mostly used in heavy alcohol drinkers who are malnourished (megaloblastic 
anemia), and to treat nerve degeneration caused by the abusive alcohol intake, as it promotes remyelination of the affected myelin sheaths. ${ }^{20}$

The population examined in this study had a higher number of cocaine users than users of marijuana and crack. Although marijuana is the most commonly used drug in Brazil, with a prevalence ranging from $2.1-74 \%$, depending on the studied population, $, 21,22$ cocaine causes greater dependence than marijuana. Furthermore, even though crack is a derivative of cocaine, it is commercially cheaper and capable of inducing dependence more easily than cocaine. The use of crack is still relatively recent in Brazil. ${ }^{8}$ Often, chemically dependent individuals are polydrug users; they concomitantly use other drugs, such as alcohol and tobacco, in addition to illicit substances. The mouth is a primary entry point for many of these agents; therefore, oral health becomes very susceptible to the synergism and the harmful effects of these substances. ${ }^{23}$ Alcohol and marijuana are less harmful to health in comparison with cocaine and crack cocaine, once the latter two can cause more psychiatric comorbidities and cognitive impairment, and are also associated with sexually transmitted diseases and involvement in illegal activities. ${ }^{9,24,25}$

The DMFT index was significantly lower in the experimental group $(p=0.0148)$. However, Mateos-Moreno et al. ${ }^{14}$ found DMFT indexes in users of legal and illegal drugs of 27.13, 14.88, and 22.7. Although the average DMFT was higher in the control group, the prevalence of caries and missing teeth was higher in the experimental group and of filled teeth was higher in the control group. This could be a consequence of higher access to dental treatment by the control group. In addition, the lack of dental care for rehabilitating drug users may have contributed to the results. Based on this analysis, the use of illicit drugs cannot be directly associated with the worsening of oral health condition. However, the biases in data analysis as well as the limitations described throughout the study development must be considered. Moreover, this difference might also be related to the differences in socio-economic status between the groups.

A significantly reduced salivary flow rate was found in the experimental group. This result corroborates other studies, ${ }^{14,26}$ however different SFR measuring methods were used in the studies, including more accurate methods of sialometry. During the routine medical visit, the quantification of passive or stimulated salivary flow rates in these patients was not possible. However, although simple, the applied test can be useful in limited situations, allowing an initial screening for cases of hyposalivation. Because the patients included in the experimental group were primarily licit and illicit polydrug users including medication for dependency treatment, the effect of a particular drug on the SFR could not be determined. Thus, it is suggested that the use of medications may have influenced the results, thereby contributing to a higher number of diagnosed cases of hyposalivation. ${ }^{27}$

A significantly higher number of patients with the presence of mucosal lesions was noted in the experimental group. However, no potentially malignant disorder or oral cancer lesion was diagnosed. Lesions found in the drug addicts consisted of aphthous stomatitis, frictional keratosis (from sharp teeth edges or morsicatio), candidiasis, tooth extraction scars, and tongue depapilation. In a previous study, a group of 64 legal and illegal drug users presented with lesions, such as candidiasis, angular cheilitis, ulcers, leukoplakia, mucositis, herpes, papilloma, and gingivitis. ${ }^{14}$

The reduced number of mucosal lesions in the control group might be due to better oral health of these individuals, who, for the most part, had normal daily functions. ${ }^{11}$ Furthermore, the high prevalence of trauma in users of illicit substances may be related to the higher number of mucosal and lip lesions in the experimental group. ${ }^{14}$ Hyperkeratinization, a modification of the epithelium that may result from a local irritant (physical, chemical, and/or thermal), or from physiological, inflammatory, immunological, potentially malignant and malignant conditions, was the most prevalent alteration observed in drug users. The effects of heat and/or chemical components from tobacco and crack smoking can probably induce this response in the epithelium. ${ }^{7}$

Regarding the duration of substance use, the experimental group consumed alcohol and tobacco for longer periods than the control group. Previous studies found that oral cancer was more prevalent in males who were smokers and drinkers, ${ }^{28,29}$ although no association was found between lifetime marijuana 
use and the risk of head and neck cancer. ${ }^{30}$ In the present study, the average duration of alcohol and tobacco use was relatively low and may explain the absence of lesions characteristic of oral cancer. Few studies indicate the specific duration of smoking and drinking that could lead to the development of oral cancer. However, because the duration of illicit drug use was even less than of legal drugs, it is likely that the absence of lesions is due to the short duration of illicit drug use in our sample. Carvalho et al. ${ }^{30}$ found no association between lifetime marijuana use and the risk for development of oral cancer, while Marks et al. ${ }^{5}$ suggested that the association of marijuana use with head and neck carcinoma may differ by tumor site. Because of the scarcity of studies and variations between them, it is difficult to define the relationship between amount of marijuana smoked and the appearance of mucosal lesions.

The main challenge of the present study was to find isolated users of illegal drugs, as few subjects did not use tobacco and/or alcohol concomitantly with marijuana and/or cocaine/crack. Because most of the subjects in the experimental group were polydrug users, no stratification was possible to evaluate the effect of each drug separately. Thus, we cannot conclude whether single drugs are more or less harmful to the oral environment. Moreover, due to the scarcity of patients in the psychiatric services in which the data were collected, the sample size of the experimental group was small. Further studies should assess single-drug users minimizing confounding factors, such as alcohol, tobacco, or their concomitant use. Larger samples would be important, however individual drug use is infrequent.

Because of the difficulties involved in studies with drug addicts, several methodologies are adopted according to the local realities. This leads to dissonant results of similar topics that can be related to differences in methodology, target population, sample size and choice of controls, low response rate, and inefficiency in quantifying drug use. ${ }^{30}$ Despite several inferences published to date, there is currently insufficient epidemiological evidence to support a positive or negative association of illicit chemical substances use and the development of oral cancer.

Research with users of illicit drugs and the treatment of these individuals is complex, and includes a psychiatric approach. Thus, biopsychosocial factors and comorbidities should be accounted for when analyzing the interferences and the variables that might be related to drug use. Nevertheless, the evaluation and needs assessment of this population is extremely important to take preventive action on the risk factors for a low quality of life.

\section{Conclusion}

From the analysis of the results, it can be concluded that users of illicit chemical substances are mostly male, with a high prevalence of smoking and drinking habits. Regarding oral health, illicit drug users showed a reduced SFR and increased number of mucosal lesions compared to the control group, but no relationship with oral cancer or potentially malignant disorders was found.

\section{Acknowledgments}

The authors thank the Psychiatric Unit of the Hospital of the Federal University of Santa Catarina (HU/UFSC) and the Psychiatric Institute of Santa Catarina (IPq/SC) that allowed access to their patients.

\section{References}

\footnotetext{
1. Gigena PC, Cornejo LS, Lescano-de-Ferrer A. Oral health in drug addict adolescents and non psychoactive substance users. Acta Odontol Latinoam. 2015;28(1):48-57. https://doi.org/10.1590/S1852-48342015000100007.

2. Cho CM, Hirsch R, Johnstone S. General and oral health implications of cannabis use.
}

\footnotetext{
Aust Dent J. 2005;50(2):70-4.

https://doi.org/10.1111/j.1834-7819.2005.tb00343.x

3. Meier MH, Caspi A, Cerdá M, Hancox RJ, Harrington H, Houts $R$ et al. Associations between cannabis use and physical health problems in early midlife: a longitudinal comparison of persistent cannabis vs tobacco users. JAMA Psychiatry. 2016;73(7):731-40. https://doi.org/10.1001/jamapsychiatry.2016.0637
} 
4. Marques TC, Sarracini KL, Cortellazzi KL, Mialhe FL, Meneghim MC, Pereira AC et al. The impact of oral health conditions, socioeconomic status and use of specific substances on quality of life of addicted persons. BMC Oral Health. 2015;15(1):38. https://doi.org/10.1186/s12903-015-0016-8

5. Marks MA, Chaturvedi AK, Kelsey K, Straif K, Berthiller J, Schwartz SM et al. Association of marijuana smoking with oropharyngeal and oral tongue cancers: pooled analysis from the INHANCE consortium. Cancer Epidemiol Biomarkers Prev. 2014;23(1):160-71. https://doi.org/10.1158/1055-9965.EPI-13-0181

6. Aldington S, Harwood M, Cox B, Weatherall M, Beckert $L$, Hansell $A$ et al. Cannabis use and cancer of the head and neck: case-control study. Otolaryngol Head Neck Surg. 2008;138(3):374-80. https://doi.org/10.1016/j.otohns.2007.12.002

7. Woyceichoski IE, de Arruda EP, Resende LG, Machado MA, Grégio AM, Azevedo LR et al. Cytomorphometric analysis of crack cocaine effects on the oral mucosa. Oral Surg Oral Med Oral Pathol Oral Radiol Endod. 2008;105(6):745-9. https://doi.org/10.1016/j.tripleo.2007.09.011

8. Lima AAS, Woyceichoski IEC, Batista AB, Gregio AMT, Ignacio $S A$, Machado MAN et al. Cytopathological changes in oral epithelium induced by crack cocaine smoking. Pharmacol Online. 2007;1:31-40.

9. Ribeiro M, Perrenoud LO, Duailibi S, Duailibi LB, Madruga C, Marques ACPR et al. The Brazilian drug policy situation: the public health approach based on research undertaken in a developing country. Public Health Rev. 2014;2:1-32.

10. Abdalla RR, Madruga CS, Ribeiro M, Pinsky I, Caetano R, Laranjeira R. Prevalence of cocaine use in Brazil: data from the II Brazilian national alcohol and drugs survey (BNADS). Addict Behav. 2014;39(1):297-301. https://doi.org/10.1016/i.addbeh.2013.10.019

11. Shekarchizadeh H, Khami MR, Mohebbi SZ, Virtanen JI. Oral health behavior of drug addicts in withdrawal treatment. BMC Oral Health. 2013;13(1):11. https://doi.org/10.1186/1472-6831-13-11

12. Hamamoto DT, Rhodus NL. Methamphetamine abuse and dentistry. Oral Dis. 2009;15(1):27-37. https://doi.org/10.1111/j.1601-0825.2008.01459.x

13. McDonald E, Marino C. Dry mouth: diagnosing and treating its multiple causes. Geriatrics. 1991;46(3):61-3.

14. Mateos-Moreno MV, Del-Río-Highsmith

J, Riobóo-García R, Solá-Ruiz MF,

Celemín-Viñuela A. Dental profile of a community of recovering drug addicts: biomedical aspects: retrospective cohort study. Med Oral Patol Oral Cir Bucal. 2013;18(4):e671-9. https://doi.org/10.4317/medoral.18669

15. Bektas-Kayhan K, Karagoz G, Kesimli MC, Karadeniz AN, Meral R, Altun M et al. Carcinoma of the tongue: a case-control study on etiologic factors and dental trauma. Asian Pac J Cancer Prev. 2014;15(5):2225-9. https://doi.org/10.7314/APJCP.2014.15.5.2225
16. Madani AH, Dikshit M, Bhaduri D, Aghamolaei T, Moosavy SH, Azarpaykan A. Interaction of alcohol use and specific types of smoking on the development of oral cancer. Int J High Risk Behav Addict. 2014;3(1):e12120. https://doi.org/10.5812/ijhrba.12120

17. Souza FB, Silva MRF, Fernandes CP, Silva PG, Alves AP. Oral cancer from a health promotion perspective: experience of a diagnosis network in Ceará. Braz Oral Res. 2014;28(n. spe):1-8. https:// doi.org/10.1590/1807-3107BOR-2014.vol28.0018

18. Madruga CS, Laranjeira R, Caetano R, Pinsky I, Zaleski M, Ferri CP. Use of licit and illicit substances among adolescents in Brazil: a national survey. Addict Behav. 2012;37(10):1171-5. https://doi.org/10.1016/i.addbeh.2012.05.008

19. Perez LG, Pratt M. Simoes EJ, de Moura L, Malta DC. Association between leisure-time physical activity and self-reported hypertension among Brazilian adults, 2008. Prev Chronic Dis. 2013;10:E172. https://doi.org/10.5888/pcd10.130032

20. Day E, Bentham PW, Callaghan R, Kuruvilla T, George $S$. Thiamine for prevention and treatment of Wernicke-Korsakoff Syndrome in people who abuse alcohol. Cochrane Database Syst Rev. 2013;(7):CD004033. https://doi.org/10.1002/14651858.CD004033.pub3.

21. Jungerman FS, Menezes PR, Pinsky I, Zaleski M, Caetano R, Laranjeira R. Prevalence of cannabis use in Brazil: data from the I Brazilian National Alcohol Survey (BNAS). Addict Behav. 2010;35(3):190-3. https://doi.org/10.1016/i.addbeh.2009.09.022

22. McLennan JD, Bordin I, Bennett K, Rigato F, Brinkerhoff $M$. Trafficking among youth in conflict with the law in São Paulo, Brazil. Soc Psychiatry Psychiatr Epidemiol. 2008;43(10):816-23. https://doi.org/10.1007/s00127-008-0365-6

23. Lopes CF, Angelis BB, Prudente HM, Souza BV, Cardoso SV, Ribeiro RIA. Concomitant consumption of marijuana, alcohol and tobacco in oral squamous cell carcinoma development and progression: recent advances and challenges. Arch Oral Biol. 2012;57(8):1026-33. https://doi.org/10.1016/i.archoralbio.2012.05.006

24. Degenhardt L, Chiu WT, Sampson N, Kessler RC, Anthony JC, Angermeyer $\mathrm{M}$ et al. Toward a global view of alcohol, tobacco, cannabis, and cocaine use: findings from the WHO World Mental Health Surveys. PLoS Med. 2008;5(7):e141. https://doi.org/10.1371/journal.pmed.0050141

25. Degenhardt L, Hall W. Extent of illicit drug use and dependence, and their contribution to the global burden of disease. Lancet. 2012;379(9810):55-70. https://doi.org/10.1016/S0140-6736(11)61138-0

26. McGrath C, Chan B. Oral health sensations associated with illicit drug abuse. Br Dent J. 2005;198(3):159-62. https://doi.org/10.1038/sj.bdj.4812050

27. Scully $C$. Drug effects on salivary glands: dry mouth. Oral Dis. 2003;9(4):165-76. https://doi.org/10.1034/j.1601-0825.2003.03967.x

28. Dias GS, Almeida AP. A histological and clinical study on oral cancer: descriptive analyses of 365 cases. Med Oral Patol Oral Cir Bucal. 2007;12(7):E474-8. 
29. Morse DE, Psoter WJ, Baek LS, Eisenberg E, Cohen D, Cleveland $\mathrm{D}$ et al. Smoking and drinking in relation to depressive symptoms among persons with oral cancer or oral epithelial dysplasia. Head Neck. 2010;32(5):578-87. https://doi.org/10.1002/hed.21227
30. Carvalho MFF, Dourado MR, Fernandes LB, Araújo CTP, Mesquita AT, Ramos-Jorge ML. Head and neck cancer among marijuana users: a meta-analysis of matched case-control studies. Arch Oral Biol. 2015;60(12):1750-5. https://doi.org/10.1016/i.archoralbio.2015.09.009 